reasons and $6.3 \%$ tested voluntarily. Testing was conducted at the health facility and laboratories in $11.3 \%$ out of the $14.6 \%$ of respondents that had been tested. Youths who had at least a secondary school education and use condoms were more likely to have been tested. Majority (78.0\%) were willing to be tested among this group, more than a third (36.8\%) will prefer to be tested within the community (workplace, school, home or mobile outreach).

Conclusion Rural youths in this study are willing to be tested for HIV. Provision of this service within the community will improve access and uptake.

\section{P17.13 EVALUATING THE IMPLEMENTATION OF COUPLES HIV COUNSELLING AND TESTING (CHCT) AMONG MOST AT RISK POPULATIONS: AN EXPERIENCE FROM BALI, INDONESIA}

1,2KA Kartika Sari ${ }^{*},{ }^{1,2} \mathrm{IN} \mathrm{Sutarsa},{ }^{1,2} \mathrm{NW}$ Septarini, ${ }^{2} \mathrm{E}$ Rowe. ${ }^{1}$ Faculty of Medicine Udayana University; ${ }^{2}$ Kerti Praja Foundation

\subsection{6/sextrans-2015-052270.591}

Introduction A pilot project of couples HIV counselling and testing (CHCT) was conducted among most-at-risk populations (MARP) in Bali from April to September 2013. The project provided financial incentives for outreach workers and counsellors during the implementation. The study evaluated the process of CHCT program and explored the readiness to continue the program implementation.

Methods A mixed method study conducted in July-December 2013. The number of couples participated during and after the project were compared. Four focus group discussions were conducted with counsellors and outreach workers, while in-depth interviews conducted with 22 couples (men who have sex with men, female sex workers and their partners).

Results There were 100 couples participated during the 6 month project (average: 16-17 couples/month). The number, however, decreased significantly with only 19 couples in the following 5 months (average: 3-4 couples/month). Due to the availability of incentives for staff, they were more active in searching and enrolling clients during the project than after the project. It was revealed that counsellors and outreach workers face more challenges in CHCT than in the individual VCT, particularly the issues of couples' separation, significantly increased workload, and a limited number of trained counsellors. Interviews with couples show the need of better services and supporting facilities such as after-hour services, treatment support system, computerised data management, one day laboratory service, and more friendly staff. Even though the level of knowledge was generally good, there were some misperceptions among couples regarding the natural history of HIV infection, thus complete information during the counselling process is required.

Conclusion CHCT among MARP in Bali can be sustainable, however, some kind of incentives and training for counsellors are needed to motivate staff, while promotion of CHCT and improved facilities are required to attract couples and to provide better services.

Disclosure of interest statement The study is funded by National AIDS Commission of Indonesia and HIV Corporation Program for Indonesia (HCPI).

\section{P17.14 BARRIERS AND FACILITATORS TO COUPLES HIV TESTING AND COUNSELLING AND VIEWS ON INCENTIVES FOR COUPLES TESTING: A QUALITATIVE STUDY FROM ZIMBABWE}

${ }^{1}$ EL Sibanda*, ${ }^{1} \mathrm{M}$ Makamba, ${ }^{2} \mathrm{~K}$ Hatzold, ${ }^{1,3} \mathrm{FM}$ Cowan. ${ }^{1}$ Centre for Sexual Health and HIVAIDS Research (CeSHHAR) Zimbabwe, Harare, Zimbabwe; ${ }^{2}$ Population Services International Zimbabwe (PSI Zimbabwe), Harare, Zimbabwe; ${ }^{3}$ Department of Infection and Population Health, University College London, London, UK

\subsection{6/sextrans-2015-052270.592}

Introduction Couples HIV testing (CHTC) has greater health impact and is more cost-effective than individual testing. Despite widespread promotion, uptake remains sub-optimal. We explored i) barriers and facilitators to CHTC, ii) anticipated impact of incentives on CHTC uptake and linkage to post-test services, iii) incentives which might stimulate CHTC.

Methods Focus group discussions (FGDs) were held among rural Zimbabweans. FGDs started with role plays depicting couples with differing circumstances to stimulate discussion and were transcribed verbatim and analysed thematically.

Results Four FGDs were held with 17 men and 17 women. Both sexes said men were opposed to CHTC; barriers were more pertinent to men. The main barrier was fear of HIV diagnosis which respondents firmly believed would result in relationship dissolution. Participants understood discordancy as possible but were unaware/had not internalised benefits of discordant couple interventions. Discussions focused on the difficulty of broaching CHTC within a relationship as it raises uncomfortable issues of distrust. Women reportedly broached CHTC if they suspected infidelity, often threatening suicide or relationship dissolution in the event they tested positive. Interventions that took the decision out of the couple's hands e.g. perceived 'mandatory testing' for prevention of mother-to-child-transmission were viewed as facilitators for CHTC. Participants unanimously agreed that incentives would make discussing CHTC easier as the focus would shift to incentives. Participants said small items such as food and soap would stimulate CHTC. Participants were against monetary incentives as these would likely be abused or lead to conflict. Small, fixed incentives were preferred over larger lottery-based incentives. Participants said couples who received incentives to test would be more likely to link to post-test services with expectation of receiving additional rewards.

Conclusion This study suggests that small non-financial incentives may increase uptake of CHTC and subsequent linkage to care. We propose to test this intervention in a cluster randomised trial.

Disclosure of interest statement The study was funded by the Integrated Support Programme and no conflicts of interest are declared.

\section{P17.15 BARRIERS AND FACILITATORS TO UPTAKE OF CERVICAL CANCER SCREENING AMONG CLIENTS ATTENDING INTEGRATED HIV/SEXUAL AND REPRODUCTIVE HEALTH CLINICS IN ZIMBABWE}

${ }^{1}$ EL Sibanda*, ${ }^{1} \mathrm{~N}$ Ruhode, ${ }^{1} \mathrm{C}$ Madanhire, ${ }^{2} \mathrm{~K}$ Hatzold, ${ }^{1,3} \mathrm{FM}$ Cowan. ${ }^{1} \mathrm{Centre}$ for Sexual Health and HIVAIDS Research (CeSHHAR) Zimbabwe, Harare, Zimbabwe; ${ }^{2}$ Population Services International Zimbabwe (PSI Zimbabwe), Harare, Zimbabwe; ${ }^{3}$ Department of Infection and Population Health, University College London, London, UK

10.1136/sextrans-2015-052270.593 